\title{
Accessory Nerve Anatomy in Anterior and Posterior Cervical Triangle: A Fresh Cadaveric Study
}

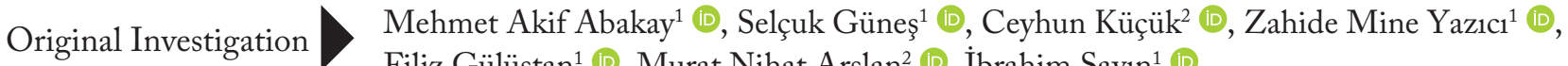 \\ Filiz Gülüstan ${ }^{1}$ (D), Murat Nihat Arslan² (D), İbrahim Sayın ${ }^{1}$ (iD \\ ${ }^{1}$ Department of Otolaryngology Head and Neck Surgery, Bakırköy Dr. Sadi Konuk Training and Research Hospital, İstanbul, Turkey \\ ${ }^{2}$ Department of Forensic Science, İstanbul Forensic Medicine Institution, İstanbul, Turkey
}

Abstract

ORCID iDs of the authors: M.A.A. 0000-0003-0413-421X; S.G. 0000-0001-9458-5799; C.K. 0000-0001-5372-3753 Z.M.Y. 0000-0002-4164-3438; F.G. 0000-0003-4857-214X; M.N.A. 0000-0002-9916-5109; i.S. 0000-0003-3388-7835.

Cite this article as: Abakay MA, Günes $S$, Küçük C, Yazıı ZM, Gülüstan F, Arslan MN, et al. Accessory Nerve Anatomy in Anterior and Posterior Cervical Triangle: A Fresh Cadaveric Study. Turk Arch Otorhinolaryngol 2020; 58(3): 149-54.

\section{Corresponding Author:}

Mehmet Akif Abakay, hacetakif@yahoo.com

Received Date: 05.03 .2020 Accepted Date: 19.05 .2020

Content of this journal is licensed under a Creative Commons Attribution 4.0 International License. Available online at www.turkarchotolaryngol.net
Objective: To understand the variations and normal course of the accessory nerve (CNXI) to help more accurate and confident neck dissection.

Methods: The course of the CNXI in the neck, its relationship to the surrounding anatomic structures and the factors affecting its course were investigated.

Results: A total of 100 neck dissections were performed on 50 fresh cadavers. Eleven division variations were observed at the anterior triangle. The location of CNXI at the posterior border of the sternocleidomastoid muscle (PBSCM) was investigated and the ratio between the distance from the mastoid apex (MAA) to CNXI at the PBSCM and the distance from MAA to the posterior border where the PBSCM is attached to the clavicle increased as height of the subject increased $(\mathrm{p}<0.05)$.

Conclusion: It must be kept in mind that it is better to search for CNXI in taller subjects more inferiorly at the posterior border of the sternocleidomastoid muscle.

Keywords: Accessory nerve, anatomy, neck dissection, Erb's point, sternocleidomastoid muscle, injury

\section{Introduction}

Accessory nerve (CNXI), the eleventh cranial nerve, passes through both the anterior and the posterior cervical triangles. Its close relation to important anatomic structures such as the internal jugular vein (IJV), the sternocleidomastoid muscle (SCM), the cervical plexus, and the greater auricular nerve (GAN), as well as its long course render CNXI prone to injury.

Neck dissections are one of the most common surgical procedures in the practice of head and neck oncology. Since first described by Crile (1), sacrificed anatomic structures lessened as surgeo$\mathrm{ns}$, in time, came to see that protecting nonlymphatic structures did not affect surgical outcomes, especially in $\mathrm{N} 0$ and mobile $\mathrm{N} 1$ neck statuses (2-4). Although CNXI is preserved in most of the suitable neck dissections, morbidity rate is still relatively high. A recently published article reported CNXI morbidity rates in radical neck dissections, selective neck dissections and modi- fied neck dissections at 46.7\%. 42.5\%, and 25\%, respectively $(5,6)$.

CNXI injury can also occur in posterior cervical triangle procedures. Especially during localized surgical procedures, relatively narrow exploration and variable course of CNXI renders the nerve prone to injury. Level Va, where CNXI exits at the posterior border of the sternocleidomastoid muscle (PBSCM), is also where injuries occur most commonly (7). Especially at the PBSCM, the distances between CNXI and the great auricular point (GAP), the nerve point, and Erb's point have been investigated (8-10). There are also current reports in the literature of CNXI injuries during neck lift operations (11).

Since CNXI injury may occur at both the anterior or the posterior cervical triangle, knowledge about the anatomy of CNXI and its relationship to the surrounding structures is important, especially for young otorhinolaryngologist, plastic surgeons, neurosurgeons and general surgeons. 
This fresh cadaveric study was carried out to evaluate the surgical landmarks and the variations regarding CNXI and its relationships with the adjacent anatomic landmarks in the anterior and posterior cervical triangles. We aimed to investigate the factors that affect the CNXI exit at the PBSCM. To the best of our knowledge, this study is the first in the literature to investigate anatomic factors affecting the CNXI exit point at the PBSCM.

\section{Methods}

The study was approved by the Ethics Committee of the Directorate of Forensic Medicine Institution of the Turkish Ministry of Justice (Approval Date: July 27, 2018; Approval Number: 21589509/2017/625).

A total of 50 adult cadavers and 100 CNXIs were evaluated. Subjects with congenital defects, neck trauma, including suicide by hanging, any type of neck incision, or a history of neck surgery/neck trauma were excluded. Because the study was conducted on fresh cadavers, subjects were also excluded if death had occurred more than 24 hours ago. Dissections were performed after the cranium, the chest, and the abdomen were examined by forensic medicine specialists. The heights of the cadavers were measured. All subjects were examined and measured with the shoulders and neck in a straight position. The head was held in perpendicular position to the neck. Measurements were made using a caliper.

The terminology used for the landmarks at the PBSCM were: GAP was the exit point of the GAN at the PBSCM; Erb's point was defined as the area $2-3 \mathrm{~cm}$ above the clavicle and one finger's length posterior to the $\operatorname{SCM}(12,13)$. The nerve point was the exit region of the cutaneous branches of the cervical plexus nerves at the PBSCM (14-16). Anatomic structures are shown in Figure 1.

A skin flap was elevated under the subplatysmal plane. First, GAN was identified, then dissection was performed cranially until CNXI was identified and the dissection was advanced up to the medial order of the trapezius muscle. The distances between five pre-determined points (mastoid apex [MAA], PBSCM attachment point to clavicle [clavicleS], GAN, nerve point, and medial border of the trapezius muscle), and CNXI at the PBSCM were measured and recorded. The distance

\section{Main Points}

- Variations of CNXI to IJV relationship are seen in about $20 \%$ of patients. First identifying the IJV, then finding the CNXI, and determining the IJV to CNXI relationship seems to be a more appropriate surgical approach.

- Failure to take into account the branches from C2-3-4 during surgery may cause shoulder problems in $3 \%$ of the patients even if the main truncus is preserved. The use of blunt dissection rather than electrocautery, and care of cervical branches during neck dissection will reduce this problem.

- The surgeon should be aware that CNXI is located more inferiorly at the PBSCM in taller subjects. of CNXI at the medial border of the trapezius muscle to the clavicle (nearest point of clavicle at 90 degrees) was recorded. Distances between MAA, the angle of mandible (MAK), and the midpoint of clavicle (clavicleM) were recorded. And finally, SCM width were measured and recorded.

After the initial measurements, IJV was dissected cranially. CNXI was identified at the level of the posterior belly of the digastric muscle. Anterior triangle course dissection was advanced until the entry of CNXI to the SCM was seen. Relationships between CNXI and IJV were recorded. CNXI length between the posterior belly at the digastric level (PBD) and SCM entrance was measured. Lastly, the intermuscular part of the CNXI was dissected.

Dissection was terminated when the course of CNXI was no longer visible.

\section{Statistical Analysis}

Statistical analysis was performed using the NCSS 11 software (Number Cruncher Statistical System, 2017 Statistical Software; Kaysville, Utah, USA). The relationships of variations to sex and SAN-IJV position were evaluated using Fisher's exact test. At the PBSCM, the muscle length from MAA to the clavicle,

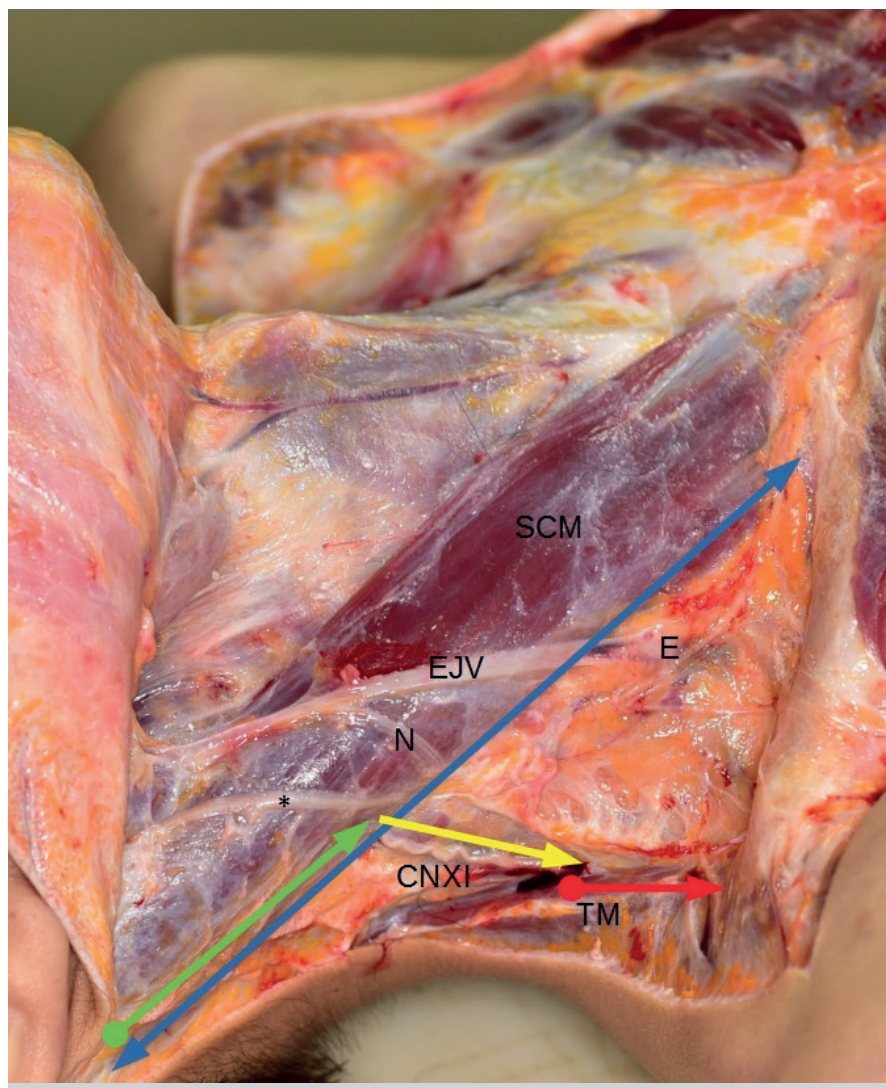

Figure 1. Anatomic structures and points seen after elevation of the subplatysmal flap, right neck

EJV: external jugular vein; CNXI: trapezial branch of accessory nerve. *: great auricular nerve; N: cutaneous branches of the cervical plexus nerves;

E: Erb's point; TM: trapezius muscle; SCM: sternocleidomastoid muscle; green arrow: MAA-CNXI at PBSCM distance; blue arrow: MAA-ClavicleS; red arrow: Trap-ClavicleN; yellow arrow: SCMpostCNXI-Trap distance 
to the GAN point, to the nerve point, and to the CNXI point were examined using the single-sample Chi-square test. To determine the estimators of CNXI at the PBSCM, simple linear and multivariate linear analyses, with both Enter and Forward methods, were carried out. Exponential and square root transformations were used for variables that did not conform to normal distribution. Analyses were made at a $95 \%$ confidence interval. A value of $p<0.05$ was accepted as significant.

\section{Results}

The study was performed bilaterally on 50 (12 females, 38 males) fresh cadavers. CNXI measurements according to reference points are given in Table 1. According to the measurements, in PBSCM, the distance between CNXI and GAN was between $0.60-2.10 \mathrm{~cm}$ in $88 \%$ of patients. The distance between CNXI and the nerve point on the PBSCM muscle was between $0.60-2.50 \mathrm{~cm}$ in $94 \%$ of patients.

In the analysis of variations, while CNXI was mostly located lateral to the IJV ( $\mathrm{n}=80,80 \%)$, in 18 cases it was located an-

Table 1. CNXI measurements according to reference points

\begin{tabular}{l|c|c}
\hline & Mean \pm SD $(\mathrm{cm})$ & Median $(\min -\max )(\mathrm{cm})$ \\
\hline Height of subjects & $170.58 \pm 8.63$ & $172.5(150-185)$ \\
\hline MAA-SCMpostCNXI & $4.22 \pm 0.84$ & $4.25(1.9-6)$ \\
\hline MAA-ClavicleS & $13.14 \pm 1.72$ & $13.3(8.8-15.9)$ \\
\hline SCMpostCNXI-GAN & $1.16 \pm 0.53$ & $1.1(0.4-2.5)$ \\
\hline SCMpostCNXI-NP & $1.28 \pm 0.62$ & $1.15(0.4-3.7)$ \\
\hline SCMpostCNXI-Trap & $4.32 \pm 1.26$ & $4.05(1.3-8.4)$ \\
\hline Trap-ClavicleN & $4.33 \pm 1.36$ & $4.3(1.6-8.3)$ \\
\hline MAA-MAK & $4.92 \pm 1.01$ & $5.2(1.8-7.2)$ \\
\hline MAA-ClavicleM & $12.57 \pm 1.61$ & $12.4(7.8-15.9)$ \\
\hline MAK-ClavicleM & $11.8 \pm 1.66$ & $11.7(6.8-15.3)$ \\
\hline PBD-SCMen & $2.55 \pm 0.86$ & $2.4(1-5.8)$ \\
\hline SCM width & $4.38 \pm 0.72$ & $4.45(2.3-6)$
\end{tabular}

CNXI: accessory nerve; MAA: mastoid apex; SCMpostCNXI: CNXI at the PBSCM; ClavicleS: posterior border attachment of SCM to clavicle; GAN: great auricular nerve; NP: nerve point; MAK: angle of the mandible; ClavicleM: midpoint of clavicle; Trap: CNXI entrance point to trapezius muscle; ClavicleN: nearest point of clavicle to Trap point; PBD: posterior belly of digastric muscle; SCMen: CNXI entrance point to SCM; SCM: sternocleidomastoid muscle terior to the IJV, and in the remaining two cases posterior to the IJV. The anterior triangle examination showed 11 (11\%) division variations. Bilateral variation was identified in one cadaver (2\%). In three of the 11 variations, connection with C2 was observed. There were no significant relationships between anterior triangle variations and sex or accessory nerve-jugular vein position.

Simple linear regression analysis and multivariate linear analysis were performed with both Enter and Forward methods. PBSCM related variables were accepted as dependent variables, e.g., MAA to CNXI distance at the PBSCM, MAA to clavicleS distances, and MAA to CNXI at the PBSCM/MAA to clavicleS ratio, and preoperatively calculable variables were accepted as independent variables, e.g., height, MAA to MAK distance, MAK to midpoint of clavicle distance, and SCM width. Statistically significant values were found and are shown in Table 2 .

\section{Discussion}

CNXI is an important anatomic structure for surgeons in head and neck surgery (17-19). Therefore, to avoid injury, the anatomic course and variations should be determined and known. In this study, the course of CNXI was demonstrated in the anterior and posterior cervical triangles, and its relationship to other anatomic structures at the PBSCM was reviewed. The results showed that the GAP is a reliable marker, and as the height of patients increases, CNXI presents more inferiorly at the PBSCM level.

One of the landmarks used to identify CNXI at the PBSCM is the MAA. In a study by Dailiana et al. (20), the results were between $4.9-6.2 \mathrm{~cm}$. Soo et al. (21) defined the ratios of MAA to CNXI at the attachment point of PBSCM/MAA-SCM to the clavicle and reported ratios between 0.1-0.6. In our study, the MAA to CNXI ratio at the PBSCM level was measured $4.22 \pm 0.84 \mathrm{~cm}$. The ratio for MAA to CNXI at the attachment point of PBSCM/MAA-SCM to the clavicle was $0.53 \pm 0.14$, and in $87 \%$ of necks, this ratio was between $0.25-0.40$, which are similar to those reported in the literature.

Aramrattana et al. (22) investigated 56 cadavers and defined the exit region of the cutaneous branches of the cervical

Table 2. Statistically significant parameters effecting CNXI exit point at the PBSCM

\begin{tabular}{|c|c|c|c|c|c|c|}
\hline & \multicolumn{2}{|c|}{ MAA-SCMpost/MAA-ClavicleS } & \multicolumn{2}{|c|}{ MAA-SCMpost } & \multicolumn{2}{|c|}{ MAA-ClavicleS } \\
\hline & Parameter & $\mathrm{p}$ & Parameter & $\mathrm{p}$ & Parameter & $\mathrm{p}$ \\
\hline \multirow[t]{2}{*}{ Simple linear regression } & \multirow[t]{2}{*}{ Height } & \multirow[t]{2}{*}{0.01} & Height & $<0.001$ & Height & $<0.001$ \\
\hline & & & MAK-ClavM & $<0.001$ & MAK-ClavM & $<0.001$ \\
\hline Multivariable linear regression & \multirow[t]{2}{*}{ Height } & \multirow[t]{2}{*}{0.003} & Height & 0.001 & Height & $<0.001$ \\
\hline Enter method & & & MAK-ClavM & 0.012 & MAK-ClavM & 0.03 \\
\hline Multivariable linear regression & \multirow[t]{2}{*}{ Height } & \multirow[t]{2}{*}{0.01} & Height & 0.015 & Height & $<0.001$ \\
\hline Forward method & & & MAK-ClavM & 0.004 & MAK-ClavM & 0.029 \\
\hline
\end{tabular}


plexus nerves at the PBSCM as Erb's point. In one (0.9\%) case, CNXI was below Erb's point, in 10 (8.9\%) at the same level, and in the remainder (90.2\%) CNXI was above Erb's point. The mean distance between Erb's point and CNXI was 1.43 $\mathrm{cm}$. Dailiana et al. (20), examined 20 cadavers and found that GAN and CNXI left the PBSCM at the same level. Mirjalili et al. (23) evaluated the distance between GAP and CNXI at the PBSCM using ultrasound and reported the CNXI to be a mean 1.1 (range, 0.1-2.1) cm superior to GAN. Raikos et al. (8) investigated the GAN to CNXI relationship at the $\mathrm{PBSCM}$ and reported the mean value as $9.2 \pm 5.46 \mathrm{~mm}$. They classified the relationship according to the exit of GAN at the PBSCM as Type A if GAN exited cranially in the mid-third of the PBSCM or at the midpoint of the PBSCM, and Type B, if caudally located. Type A was found to be twice as common as Type B. In our study, Type A was determined at the rate of 96\%. This difference may be due to the position and the technique used.

Dailiana et al. (20) measured the trapezius entrance of CNXI to the mid-point of the clavicle as a mean $5.2 \mathrm{~cm}$ (range 4.8-7 $\mathrm{cm})$. The trapezius entrance of CNXI to the nearest point of

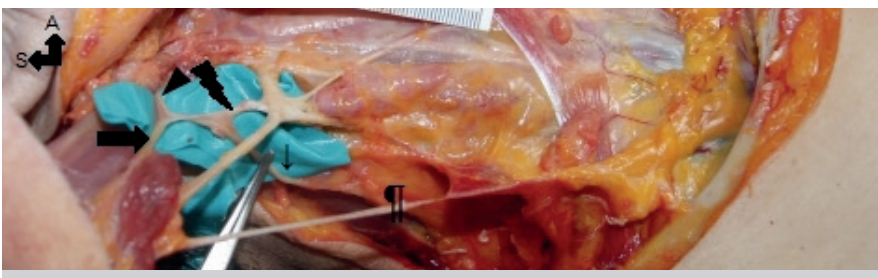

Figure 2. Division variation in anterior triangle and connection with $\mathrm{C} 2$ nerve (right neck, sternocleidomastoid muscle clavicular attachments cut and muscle pulled laterally)

I: External jugular vein; : accessory nerve; thin arrow: trapezial branch of accessory nerve; thick arrow: sternocleidomastoid branch of accessory nerve; lightning: connection between CNXI and C2

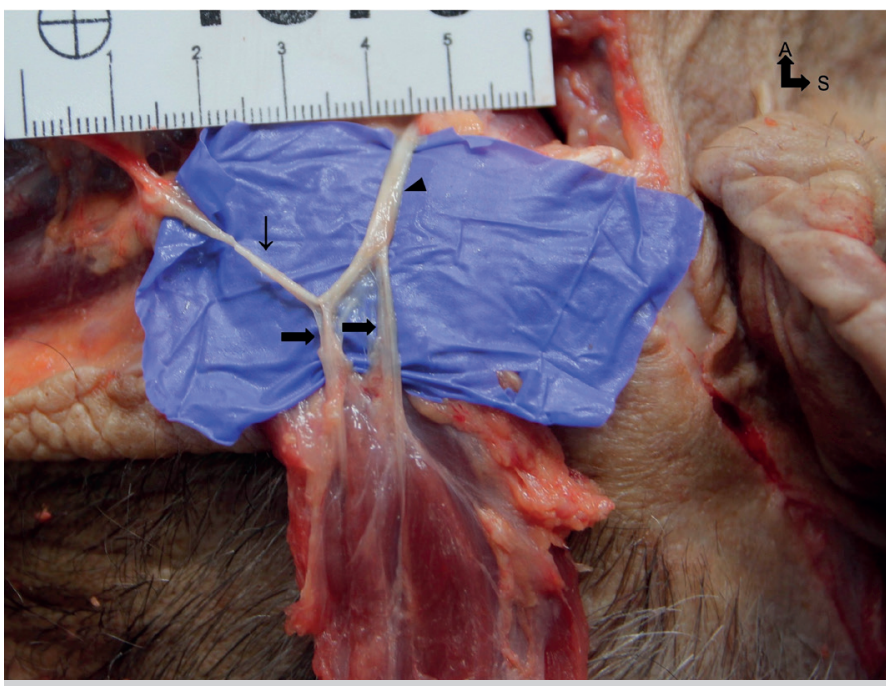

Figure 3. Division variation in anterior triangle with double entrance to sternocleidomastoid muscle (left neck, SCM clavicle attachments cut and muscle pulled laterally)

: accessory nerve; thin arrow: trapezial branch of accessory nerve; thick arrow: sternocleidomastoid branch of accessory nerve the clavicle at 90 degrees should be measured since it could be more useful surgically. This value was mean $4.33 \pm 1.36 \mathrm{~cm}$ in our study.

The anatomic proximity of CNXI to the IJV at the posterior belly of the digastric muscle is extremely important. Any injury could cause mortality because the IJV is very close to the base of skull at this point. Saman et al. (14) investigated the relationship of CNXI to the IJV. At the level of the posterior belly of the digastric muscle, $79.8 \%$ of 84 cadaver necks were found to be lateral, $19 \%$ posterior, and $1.2 \%$ of the piercing type. Taylor et al. (24) investigated this relationship in 207 surgical dissections and found $96 \%$ lateral and 3\% medial to the IJV location. CNXI piercing was determined in two (0.9\%) cases, and this variation needs extra care during surgery. In our study, non were identified to be of the piercing type, however, the piercing type variation was addressed in one of our previous studies (25).

Other results in our study were similar to those reported in the literature. There was no statistical relationship between the position and the presence of anterior triangle variations $(p>0.05)$. Brennan et al. (26) investigated division variations of CNXI in the anterior triangle in 133 neck dissections. The authors reported three division variations: one patient had superior and inferior divisions connecting with the $\mathrm{C} 2$ nerve, one had $\mathrm{C} 2$ nerve connection only with inferior division, and one had no cervical plexus connections.

Lanisnik et al. (27) analyzed the CNXI to SCM relationship. They observed type 1 (66\%) where the CNXI exited at the posterior end of the SCM, type 2 (22\%) with anterior triangle division, and type $3(12 \%)$ where the CNXI exited at the posterior end of the SCM and joined the cervical plexus continuing as a single branch. The $\mathrm{C} 2$ branch was identified to connect with the trapezial branch in all dissections (100\%). Lee et al. (28) investigated this relationship in 181 neck dissections and reported that the CNXI sent branches without penetrating

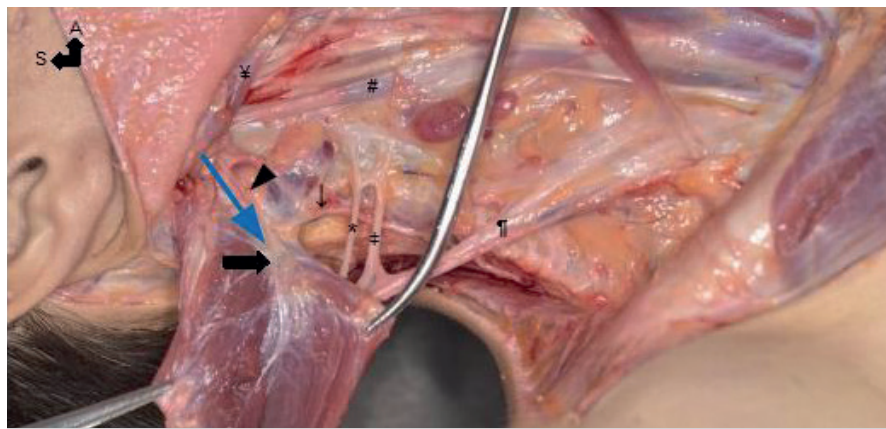

Figure 4. Division in anterior triangle and relationship to other anatomic structures (right neck, SCM clavicle attachments cut and muscle pulled laterally)

$¥:$ posterior belly of digastric muscle, 9 : external jugular vein; \#: internal jugular vein; : accessory nerve; thin arrow: trapezial branch of accessory nerve; thick arrow: sternocleidomastoid branch of accessory nerve; *: great auricular nerve; ‡: cutaneous branches of the cervical plexus nerves; blue arrow: PBD-SCMen 
the SCM muscle in $45.9 \%$ of patients. Contributions from the cervical plexus $\mathrm{C} 2, \mathrm{C} 3$, and $\mathrm{C} 4$ were $53.1 \%, 38.1 \%$, and $8.8 \%$, respectively. In the presented study, $11 \%$ division variations were observed in the anterior cervical triangle. In three, a connection with the $\mathrm{C} 2$ nerve was identified (Figure 2), and in one neck, a division variation with a double entrance to the SCM muscle was detected (Figure 3). A CNXI course with division variation is shown in Figure 4.

The information in the literature about cervical plexus contribution to the trapezius function is controversial (29). Cervical plexus branches either merge with CNXI or directly take course to the trapezius muscle. Therefore, in addition to CNXI, the cervical plexus must also be protected.

In the analyses of the non-variated 89 dissections, the mean length between the CNXI entry point to the SCM and the SCM anterior border was measured as $2.33 \pm 0.65 \mathrm{~cm}$. After providing branches to the SCM, the trapezial branch left at $1.18 \pm 0.51 \mathrm{~cm}$ posteroinferiorly. Therefore, when performing neck dissection, surgeons must continue the posteroinferior dissection carefully to avoid distal CNXI injury.

\section{Conclusion}

Because of the high rate of variations, it can be difficult to define a single, simple accurate landmark to directly locate the CNXI during neck dissection. In the PBSCM, knowing that CNXI is $2 \mathrm{~cm}$ above the GAP point in $89 \%$ of patients will help the surgeon. It must also be kept in mind that it is better to search for CNXI in taller subjects more inferiorly at the PBSCM.

Ethics Committee Approval: Ethics committee approval was received for this study from the Ethics Committee of the Directorate of Forensic Medicine Institution of the Turkish Ministry of Justice (Approval Date: July 27, 2018; Approval Number: 21589509/2017/625).

Informed Consent: Informed consent was not obtained due to the nature of this study.

Peer-review: Externally peer-reviewed.

Author Contributions: Concept - M.A.A., S.G., Z.M.Y., F.G., İ.S.; Design - M.A.A., C.K., M.N.A., İ.S.; Supervision - M.A.A., S.G., C.K., Z.M.Y., F.G., M.N.A., İ.S.; Materials - M.A.A., S.G., C.K., Z.M.Y., F.G., M.N.A., İ.S.; Data Collection and/or Processing - M.A.A., C.K., M.N.A., İ.S.; Analysis and/or Interpretation M.A.A., S.G., C.K., Z.M.Y., F.G., M.N.A., İ.S.; Literature Search - M.A.A., S.G., Z.M.Y., F.G., I.S.; Writing - M.A.A., S.G., Z.M.Y., F.G., M.N.A., İ.S.; Critical Reviews - M.A.A., C.K., F.G., M.N.A., İ.S.

Conflict of Interest: The authors have no conflicts of interest to declare.

Financial Disclosure: The authors declared that this study has received no financial support.

\section{References}

1. Crile G. Excision of cancer of the head and neck. With special reference to the plan of dissection based on one hundred and thirty-two operations. JAMA 1906; 47: 1780-6. [Crossref]

2. Dargent M, Papillon J. Motor complications of neck dissection: how to avoid them. Lyon Chir 1945; 40: 718.

3. Bocca E, Pignataro O, Sasaki CT. Functional neck dissection. A description of operative technique. Arch Otolaryngol 1980; 106: 524-7. [Crossref]

4. Bocca E, Pignataro O, Oldini C, Cappa C. Functional neck dissection: an evaluation and review of 843 cases. Laryngoscope 1984; 94: 942-5. [Crossref]

5. Poposvki V, Benedetti A, Popovic-Monevska D, Grcev A, Stamatoski A, Zhivadinovik J. Spinal accessory nerve preservation in modified neck dissections: surgical and functional outcomes. Acta Otorhinolaryngol Ital 2017; 37: 368-74.

6. Goldstein DP, Ringash J, Bissada E, Jaquet Y, Irish J, Chepeha D, et al. Scoping review of the literature on shoulder impairments and disability after neck dissection. Head Neck 2014; 36: 299308. [Crossref]

7. Park SH, Esquenazi Y, Kline DG, Kim DH. Surgical outcomes of 156 spinal accessory nerve injuries caused by lymph node biopsy procedures. J Neurosurg Spine 2015; 23: 518-25. [Crossref]

8. Raikos A, English T, Yousif OK, Sandhu M, Stirling A. Topographic anatomy of the great auricular point: landmarks for its localization and classification. Surg Radiol Anat 2017; 39: 535-40. [Crossref]

9. Symes A, Ellis H. Variations in the surface anatomy of the spinal accessory nerve in the posterior triangle. Surg Radiol Anat 2005; 27: 404-8. [Crossref]

10. Tubbs RS, Salter EG, Wellons III CJ, Blount JP, Oakes WJ. Superficial landmarks for the spinal accessory nerve within the posterior triangle. J Neurosurg Spine 2005; 3: 375-8. [Crossref]

11. Seror P. Accessory nerve lesion after cervicofacial lift: clinical and electrodiagnostic evaluations of two cases. Muscle Nerve 2009; 39: 400-5. [Crossref]

12. Tubbs RS, Loukas M, Salter EG, Oakes WJ. Wilhelm Erb and Erb's point. Clin Anat 2007; 20: 486-8. [Crossref]

13. Landau SI. International dictionary of medicine and biology, in three volumes. 1st ed. New York: John Wiley \& Sons; 1986.

14. Saman M, Etebari P, Pakdaman MN, Urken ML. Anatomic relationship between the spinal accessory nerve and the jugular vein: a cadaveric study. Surg Radiol Anat 2011; 33: 175-9. [Crossref]

15. Johal J, Iwanaga J, Tubbs K, Loukas M, Oskouian RJ, Tubbs RS. The accessory nerve: A comprehensive review of its anatomy, development, variations, landmarks and clinical considerations. Anat Rec 2019; 302: 620-9. [Crossref]

16. Lloyd S. Accessory nerve: anatomy and surgical identification. J Laryng Otol 2007; 121: 1118-25. [Crossref]

17. Becker GD, Parell GJ. Technique of preserving the spinal accessory nerve during radical neck dissection. Laryngoscope 1979; 89: 827-31. [Crossref]

18. Nahum AM, Mullally W, Marmor L. A syndrome resulting from radical neck dissection. Arch Otolaryngol 1961; 74: 424-8. [Crossref]

19. Skolnik EM, Tenta LT, Wineinger DM, Tardy ME Jr. Preservation of XI cranial nerve in neck dissections. Laryngoscope 1967; 77: 1304-14. [Crossref]

20. Dailiana ZH, Mehdian H, Gilbert A. Surgical anatomy of spinal accessory nerve: is trapezius functional deficit inevitable after division of the nerve? J Hand Surg Br 2001; 26: 137-41. [Crossref] 
Abakay et al.

21. Soo KC, Hamlyn PJ, Pegington J, Westbury G. Anatomy of the accessory nerve and its cervical contributions in the neck. Head Neck Surg 1986; 9: 111-5. [Crossref]

22. Aramrattana A, Sittitrai P, Harnsiriwattanagit K. Surgical anatomy of the spinal accessory nerve in the posterior triangle of the neck. Asian J Surg 2005; 28: 171-3. [Crossref]

23. Mirjalili AS, Muirhead JC, Stringer MD. Ultrasound visualization of the spinal accessory nerve in vivo.J Surg Res 2012; 175: 11-6. [Crossref]

24. Taylor CB, Boone JL, Schmalbach CE, Miller FR. Intraoperative relationship of the spinal accessory nerve to the internal jugular vein: variation from cadaver studies. Am J Otolaryngol 2013; 34: 527-9. [Crossref]

25. Abakay MA, Şimşek BM, Olgun B, Türkay R, Güneş S. Ultrasonic identification of internal jugular vein fenestration. Surg Radiol Anat 2019; 41: 1079-81. [Crossref]
26. Brennan PA, Blythe JStJ, Alam P, Green B, Parry D. Division of the spinal accessory nerve in the anterior triangle: a prospective clinical study. Br J Oral Maxillofac Surg 2015; 53: 633-6. [Crossref]

27. Lanisnik B, Zargi M, Rodi Z. Identification of three anatomical patterns of the spinal accessory nerve in the neck by neurophysiological mapping. Radial Oncol 2014; 48: 387-92. [Crossref]

28. Lee SH, Lee JK, Jin SM, Kim JH, Park IS, Chu HR, et al. Anatomical variations of the spinal accessory nerve and its relevance to level IIb lymph nodes. Otololaryngol Head Neck Surg 2009; 141: 639-44. [Crossref]

29. Kierner AC, Zelenka I, Heller S, Burian M. Surgical anatomy of the spinal accessory nerve and the trapezius branches of the cervical plexus. Arch Surg 2000; 135: 1428-31. [Crossref] 